\title{
A Keynesian Model of a Small Open Economy under a Flexible Exchange Rate
}

\author{
Masayuki Otaki \\ Institute of Social Science, University of Tokyo, Tokyo, Japan \\ Email: ohtaki@iss.u-tokyo.ac.jp
}

Received May 1, 2012; revised June 5, 2012; accepted July 3, 2012

\begin{abstract}
This article considers the international diffusion of business cycles on the basis of a rigorous dynamic microeconomic foundation. The seminal work of Laursen and Metzler [1] suggests that the employment-isolation effect under the flexible exchange rate system is imperfect even if international capital mobility is completely prohibited. Assuming a small country model rather than the two-country model of Laursen and Metzler [1], we obtain the following results. 1) The business fluctuation of the world economy diffuses to the small country through a change in the inflation rate caused by the change in the real exchange rate. In this sense, the employment isolation is imperfect; 2) Domestic monetary expansion has only an effect weaker than that of Mundell [2]-Fleming [3]. This is because a monetary expansion, which always accompanies a fiscal expansion, raises the current domestic price and lowers the inflation rate as long as the purchasing power of money (the inverse of future price) is kept intact. Such disinflation reduces the consumption demand in addition reducing the expansionary multiplier effect.
\end{abstract}

Keywords: Employment-Isolation Effect; Laursen-Metzler Effect; An Open Macroeconomic Model with Analytical and Dynamic Microeconomic Foundation

\section{Introduction}

The international transmission of business cycles is a serious problem under the flexible exchange rate system. We analytically (i.e., without the use of the numerical method adopted, for example, by Obstfeld and Rogoff [4]) consider this problem on the basis of an overlappinggenerations model (OLG model) with a rigorous dynamic microeconomic foundation developed by Otaki [5-7].

Generally, in two-period OLG models with no bequest motive, the capital account must always equilibrate. This is because the supply of the foreign currency by older individuals in the rest of the world should always be equal to the demand for that same currency by younger individuals in the home country. That is, capital movement is impossible due to the difficulty of the double coincidence of wants. This is a persuasive property of the long-run structure of the foreign exchange market of a small open country that cannot enjoy the economic rent of international currency including seigniorage. ${ }^{1}$

The two-country model on the international diffusion of business cycles developed in Laursen and Metzler's [1] seminal work assumes that international capital movement is prohibited. Although their model is not based on

${ }^{1}$ For the analysis concerning the key-currency country, see Otaki [8]. a neoclassical microeconomic foundation, it still has important implications. In particular, the model emphasizes the effect of the terms of trade (i.e., the inverse of the real exchange rate) on the domestic consumption resulting from the change in the fiscal expenditure.

Nevertheless, because of the lack of a microeconomic foundation, the obtained result is ambiguous and crucially depends on unknowable parameters. We resolve this problem by using some new methods. The most important factor in our theory is the manner in which the terms of trade affect both the real reservation wage and the domestic inflation rate.

Whenever the real exchange rate appreciates because of an exogenous increase in exports that is accompanied by a worldwide upturn, that appreciation favors employees because it decreases the cost of living. However, as long as the domestic economy is in imperfect unemployment equilibrium and employees have no wage bargaining power, the current nominal (reservation) wages are reduced and the price level decreases.

Nevertheless, if the purchasing power of money (the inverse of the future price level) is kept constant (According to Otaki [7], in such a situation by referring to money as credible), then the equilibrium inflation is accelerated because the future good becomes more ex- 
pensive compared than the current good. Thus, future nominal wages simultaneously grow more rapidly. This movement of nominal wages is consistent with that of the price level dominated by its marginal costs.

This accelerated inflation stimulates the consumption of the current goods under some plausible assumption concerning the utility function, thereby increasing employment. Consequently, the foreign business cycle diffuses into the domestic economy with the change in consumption caused by the terms of trade effect (i.e., the Laursen-Metzler effect), even if the international capital movement is infeasible.

An important economic factor in our model is money, which Laursen and Metzler [1] do not consider. We can analyze how the domestic monetary expansion affects the economic activity in that country. A monetary expansion brings about two effects in the domestic economy. One is a direct effect that stimulates the economy through the multiplier effect introduced by Otaki $[5,6]$.

The other is an indirect effect that affects the economy through change in the inflation rate. A monetary expansion raises the current domestic price and decreases the inflation rate as long as money is credible. This incentives the younger generation to save and lessens their consumption. Such increased savings are partly directed toward the demand for foreign currency, and hence the real exchange rate depreciates to promote more exports. However, the increased savings are not entirely absorbed by enhancing exports, and thus, increased savings toward domestic currency exceed the money supply from the domestic older generation. Hence, the multiplier process creates downward pressure on the GDP.

Thus, the indirect effect conversely reduces economic activity. Accordingly, the power of monetary policy is weakened under the flexible exchange rate. This result contrasts that of the Mundell [2]-Fleming [3] model, which allows for perfect international capital mobility.

The remainder of this paper is organized as follows: In Section 2, we construct the basic model. In Section 3 deals with comparative statics. Finally, in Section 4, we present brief concluding remarks.

\section{The Model}

\subsection{The Structure of the Model}

We consider a small open economy and assume that 1) the economy behaves as if the international price of the foreign good is exogenously given, and that 2) the global inflation rate is not affected by domestic affairs such as a change in monetary policy.

This economy specializes in single good production (good a). Since numerous firms produce goods, the market is under perfect competition. In addition, there is the other good produced in foreign countries $(\operatorname{good} b)$.
The economy imports good $b$ as a price taker. Furthermore, both goods are perishable.

At the beginning of each period, individuals are born with Lebesgue measure 1, and they live in two periods. They can supply unit labor at their discretion only when they are young. Unit labor produces unit good $a$.

There are two currencies a (the domestic currency) and $b$ (the world currency). Exchanging the same type of currency is required for purchasing some type of good. Although it is not a necessary assumption, for simplicity, we assume that the trade between members of younger generations can be done by barter. The balance of payment of this small economy $B$ becomes

$$
B \equiv p^{a}\left[E_{1}^{a}+E_{2}^{a}\right]-\pi p^{b}\left[M_{1}^{b}+M_{2}^{b}\right]
$$

where $p^{a}$ is the domestic price of $\operatorname{good} a . \pi$ and $p^{b}$ denote the nominal exchange rate and the international price of $\operatorname{good} b$, respectively. $E_{i}^{a}$ is the export volume toward the foreign $i$-th generation

( $i=1$ (young), 2(old) ). $M_{i}^{b}$ is the $i$-th generation's import volume.

Since loand within the same generation are infeasible, $p^{a} E_{1}^{a}=\pi p^{b} M_{1}^{b}$ holds. Thus, Equation (1) is transformed into

$$
B \equiv p^{a} E_{2}^{a}-\pi p^{b} M_{2}^{b}
$$

That is, the balance of payment is equal to the difference between the sum of the supply of currency $b$ from the older generation in a foreign country and the demand for the same currency of the younger generation in this economy preparing for their retirements. Since the latter generation can never trade later, Equation (2) takes the value zero.

\subsection{Optimization Problem of Each Economic Agent}

\subsubsection{Individuals}

Each individual has an identical utility function $U$ :

$$
\begin{aligned}
& U \equiv u\left(c_{1}, c_{2}\right)-\delta \alpha, \quad c_{i} \equiv\left[a_{i}\right]^{\beta}\left[b_{i}\right]^{1-\beta} \\
& 0<\beta<1 .
\end{aligned}
$$

$c_{i}$ is the aggregate consumption level during the $i$-th stage of life. $a_{i}$ and $b_{i}$ are the consumption levels of goods $a$ and $b$ respectively. $a$ denotes the disutility of labor. $\delta$ is a definition function that takes the value unity when employed and zero when unemployed. $u(\cdot)$ is a well behaved homothetic utility function concerning the consumption stream.

An elementary calculation yialds the corresponding expenditure function $\Phi$ :

$$
\Phi \equiv \phi\left(\left[p_{1}^{a}\right]^{\beta}\left[\pi_{1} p_{1}^{b}\right]^{1-\beta},\left[p_{2}^{a}\right]^{\beta}\left[\pi_{2} p_{2}^{b}\right]^{1-\beta}\right) f(u)
$$

where $u$ is a utility level. Since $\phi$ is a linear homo- 
genous function, we can transform (4) into

$$
\begin{aligned}
\Phi & =p_{1}^{a} \phi\left(e_{1}^{1-\beta}, \rho^{a} \cdot e_{2}^{1-\beta}\right) f(u) \\
& =p_{1}^{a}\left[e^{*}\right]^{1-\beta} \phi\left(1, \rho^{a}\right) f(u)
\end{aligned}
$$

where $\rho^{a}$ is the equilibrium inflation rate of the domestic good. $e^{*}$ is the stationary equilibrium real exchange rate, where stationary means that the fluctuation of the real exchange rate $e$ has converged, and hence $e_{1}=e_{2}$ holds.

From Equations (3) and (5), we can obtain the nominal reservation wage $W^{R}$ as

$$
W^{R}=p_{1}^{a}\left[e^{*}\right]^{1-\beta} \phi\left(1, \rho^{a}\right) f(\alpha)
$$

The equilibrium nominal wage is equal to $W^{R}$ as long as the economy is in an underemployment equilibrium. It is the market clearing condition for the labor market.

\subsubsection{Firms}

Since all firms are assumed to be price takers with a linear production function and unit productivity, the zero profit condition corresponds to the solution of the maximization problem. Thus, we obtain

$$
p_{1}^{a}=W^{R} \Rightarrow 1=\left[e^{*}\right]^{1-\beta} \phi\left(1, \rho^{a}\right) f(\alpha)
$$

Since $\phi$ is an increasing function of $\rho^{a}$, Equation (7) clearly shows that the inflation is accelerated whenever the real exchange rate $e^{*}$ appreciates.

\subsubsection{The Government}

In accordance with Otaki [5-7], the government keeps the real cash $m_{i} \equiv \frac{M_{i}}{p_{i}^{a}}$ constant over time once it sets the initial value $m_{1}$. Hence the budget constraint of the government becomes

$$
g=\left[1-\frac{1}{\rho^{a}}\right] m_{1}
$$

where $g$ is the wasteful real government expenditure.

\subsection{Market Equilibrium}

Our model contains four markets: the domestic good market, labor market, domestic money market, and the foreign exchange market. By Walras' law, we abbreviate the equilibrium condition for the domestic money market. The labor market is in an interior equilibrium iff Equation (6) holds.

The foreign exchange market is cleared iff $B$ in Equation (2) is equal to zero. Again, elementary calculation yields

$$
\begin{aligned}
& E_{2}^{a}=\beta\left[1-c^{b}\left(\rho^{b}\right)\right] e^{*} y^{b}, \\
& e^{*} M_{2}^{b}=[1-\beta]\left[1-c^{a}\left(\rho^{a}\right)\right] y^{a}
\end{aligned}
$$

where $c^{j}(j=a, b)$ is each economy's marginal propensity to consume. $b^{j}$ is the real GDP in terms of each economy's good. Accordingly, we obtain the following equation as the equilibrium condition for the foreign exchange market:

$$
\beta\left[1-c^{b}\left(\rho^{b}\right)\right] e^{*} y^{b}=[1-\beta]\left[1-c^{a}\left(\rho^{a}\right)\right] y^{a}
$$

Taking Equation (9) into consideration, the domestic good market is in equilibrium when

$$
y^{a}=c^{a}\left(\rho^{a}\right) y^{a}+m_{1}
$$

holds. Here, $c^{a}\left(\rho^{a}\right)$ is the economy's marginal propensity to consume.

In sum, we have three endogenous variables:

$\left(y^{a}, \rho^{a}, e^{*}\right)$. These variables are determined by Equations (7), (9), and (10) respectively. Thus, the model is completely closed.

\section{Comparative Statics}

\subsection{The Diffusion of the World Economy's Business Cycle}

We consider the effect of the world economy's business cycle on the domestic economy. The rigorous discussion is presented in the Mathematical Appendix. Assume that the world economy is upturned and that $y^{b}$ increases. This upturn directly stimulates exports and results in the appreciation of the real exchange rate $e^{*}$. This appreciation benefits employees because the import price is lowered. However, in the imperfect employment equilibrium, where some employees are unemployed, there is a room for firms to reduce the nominal wage, and thus the price of the current domestic good $p_{1}^{a}$ is also lowered.

As long as money is credible and its purchasing power $\frac{1}{p_{2}^{a}}$ is maintained, inflation is accelerated. Hence, if $\frac{\mathrm{d} c^{a}}{\mathrm{~d} \rho}$ is positive, the real effective demand $y_{a}$ increases and the upturn of the world economy diffuses to the domestic economy. In this sense, the employment-isolation effect is certainly incomplete under the flexible exchange rate system.

\subsection{The Monetary Expansion}

Let us consider the effect of the domestic monetary expansion (i.e., an increase in $m_{1}$ ). Contrary to the Mundell [2]-Fleming [3] model, our model suggests that the effect 
of the domestic monetary expansion becomes weaker, or even ambiguous when the intertemporal substitution of the consumption stream is adequately high.

Equation (10) clearly shows that, ceteris paribus, a monetary expansion increases the real GDP $y^{a}$ through the multiplier effect formulated by Otaki [5]. Nevertheless, this expansion raises the current price $p_{1}^{a}$.

When money is credible, and equivalently, the purchasing power of money $\frac{1}{p_{2}^{a}}$ is unaffected by the nominal money supply, the inflation rate $\rho^{a}$ is reduced, savings of the the younger generation are increased. Although these savings are partly directed to the foreign currency and promote export via the depreciation of the real exchange rate, the other part of the increased savings remains in the home country. such savings staying in domestic economy oppresses the multiplier effect.

Accordingly, an easy monetary policy has a weaker effect than that in the Mundell [2]-Fleming [3] model in sense that a monetary expansion has a depressive side effect concerning the rate of return from money.

\section{Concluding Remarks}

In this paper, we construct a small open economy model on the basis of the two-period overlapping generation model developed by Otaki [5-7]. The results obtained are as follows.

First, the employment-isolation effect in the flexible exchange rate system, which is ambiguous in Laursen and Metzler [1], is imperfect. This is because the appreciation of the real exchange rate accelerates domestic inflation. Moreover, the accelerated inflation stimulates the aggregate consumption and the real effective demand.
Second, the power of monetary policy in an open economy is weaker than in the Mundell [2]-Fleming [3] model. This is because, besides a depreciation in the real exchange rate, a monetary expansion brings about disinflation that is not taken into consideration in the Mundell [2]-Fleming [3] model.

\section{REFERENCES}

[1] S. Laursen and L. Metzler, "Flexible Exchange Rates and the Theory of Employment," Review of Economics and Statistics, Vol. 32, 1950, pp. 281-299. doi: $10.2307 / 1925577$

[2] R. A. Mundell, "Capital Mobility and Stabilization Policy under Fixed and Flexible Exchange Rates," Canadian Journal of Economics and Political Science, Vol. 29, No. 4, 1963, pp. 475-485. doi:10.2307/139336

[3] J. M. Fleming, "Domestic Fiscal Policies and Floating Exchange Rates," IMF Staff Papers, Vol. 9, 1962, pp. 369-380. doi: $10.2307 / 3866091$

[4] M. Obstfeld and K. Rogoff, "Foundations of International Economics," MIT Press, Cambridge, 1996.

[5] M. Otaki, "The Dynamically Extended Keynesian Cross and the Welfare-Improving Fiscal Policy," Economics Letters, Vol. 96, No. 1, 2007, pp. 23-29. doi:10.1016/j.econlet.2006.12.005

[6] M. Otaki, "A Welfare Economics Foundation for the Full-Employment Policy," Economics Letters, Vol. 102, No. 1, 2009, pp. 1-3. doi:10.1016/j.econlet.2008.08.003

[7] M. Otaki, "A Pure Theory of Aggregate Price Determination," Theoretical Economics Letters, Vol. 1, No. 3, 2011, pp. 122-128. doi:10.4236/tel.2011.13026

[8] M. Otaki, "On the Function of Key Currency," DBJ Discussion Paper Series No. 1102, Research Institute of Capital Formation, Development Bank of Japan, Tokyo, 2011. 


\section{Mathematical Appendix}

In this appendix, we show the mathematical results concerning propositions in Section 3. We have three structural Equations: (7), (9), (10). Since Roy's identity induces us to $\frac{\phi^{\prime}}{\phi}=s^{a} \equiv 1-c^{a}$, Equation (7) is transformed into

$$
[1-\beta] \frac{\mathrm{d} e}{e}+\rho \mathrm{s}^{a}(\rho) \frac{\mathrm{d} \rho}{\rho}=0 .
$$

Differentiating both sides of Equations (9) and (10) and substituting (11), we obtain

$$
\left[\begin{array}{cc}
1 & -\eta+\frac{\rho s^{a}}{1-\beta} \\
s^{a} y^{a} & -\rho\left[c^{a}\right]^{\prime} y^{a}
\end{array}\right]\left[\begin{array}{c}
\frac{\mathrm{d} y^{a}}{y^{a}} \\
\frac{\mathrm{d} \rho}{\rho}
\end{array}\right]=\left[\begin{array}{c}
\frac{\mathrm{d} y^{b}}{y^{b}} \\
\mathrm{~d} m
\end{array}\right]
$$

where

$$
\eta \equiv-\rho\left[s^{a}\right] s^{a}
$$

Solving (12), we finally obtain

$$
\left[\begin{array}{c}
\frac{\mathrm{d} y^{a}}{y^{a}} \\
\frac{\mathrm{d} \rho}{\rho}
\end{array}\right]=\frac{1}{\Delta}\left[\begin{array}{cc}
\rho\left[s^{a}\right] y^{a} & \eta-\frac{\rho s^{a}}{1-\beta} \\
-s^{a} y^{a} & 1
\end{array}\right]\left[\begin{array}{c}
\frac{\mathrm{d} y^{b}}{y^{b}} \\
\mathrm{~d} m
\end{array}\right]
$$

where

$$
\Delta \equiv-\frac{\rho y^{a}\left[s^{a}\right]^{2}}{1-\beta}<0 .
$$

